Na experiência com clínica psicanalítica de crianças num serviço público de saúde mental ao lango das últ timos anos, temos nos deparado com uma desproporção entre o número de meninos e meninas encaminhados para tratamento psicoterapâtico com sintamas escolares, sendb significativamente maior o número de guris. O que faz dos meninos, na atualidade, tão avessos à escola? ar será a escola avessa a algo da mascul inidade que está em causa ali? O que produz este conflito, elevado à máxima potência em muitos casos que são encaminhados para a clínica, na espera de que "domestiquemos" estas crianças? Estará havendo uma tentativa de apagamento da diferença, o que faz com que ela ressurja no espaço escolar como violência e transgressão? Como constroem os meninos modelos de identificação, se não podem diferenciar-se num universo maciçamente feminino?

Clínica psicanalítica; escola; funções parentais; agressividade; identificação; diferença sexual

IN ORDER TO BE A BOY: SPACE AND REPRESENTATION OF MASCULINITY AT SCHOOL Or experience withpsychoanalytic clinic of dritoren in apblic mental heal th service during the late years has shown us a large difference between then nuber of boys andgirls assigned to psychotherapy due to school problems. The number of boys is considerably higher. What makes boys so averse school today? Or would school be averse sonething of masarlinity that is canveyed here? What causes this conflict that is specially hard in sane individrals uto are assigned to psych the rapy as a wery to be tamed? hould it bede to anattent toerase the difference, so that it retums as violence and transgressionat scho ol? How do boys buil d models of identification if they cam t be different amang a strangly feminineuniverse?

Psychoanalytic clinic; school; parental finctions; aggressive ness; identification; senel difference

\section{PARA SER UM GURI : ESPAÇO E REPRESENTAÇÃO DA MASCULINIDADE NA ESCOLA ${ }^{1}$}

\author{
Ieda Prates da Silva
}

primeiro lugar, gostaria de fazer referência ao título, que me veio da lembrança do trabalho de uma estagiária de psicologia de nosso serviço - agora já psicóloga - sobre um caso clínico atendido por ela, que eu pude acompanhar em supervisão, e ajo atravessamento do trabalho analítico produziu uma qperação subjetiva que ela intitulou "para ser um guri" . Esta expressão pareceu-me muito pertinente para a questão que desenvolvo neste artigo, e tomei-a emprestada da referida colega? .

Na experiência com clínica psicanalítica de crianças num serviço público de saúde mental ao longo dos últimos anos, temos nos deparado com uma realidade que para mim levanta questões instigantes e que o tema do Congresso da APPOA, $A$ Mascullinidade, me oportunizou trabalhar: o número de meninos, principalmente na faixa dos 8 aos 12 anos, encaminhados para tratamento psicoterapêutico com sintomas escolares (agressivida-

- Psicanalista, membro da Associação Psicanalítica de Porto Alegre - APPOA; fundadora do Serviço de Atendimento à Criança e ao Adolescente Françoise Dolto, da Secretaria de Saúde de Novo Hamburgo. 
de, distúrbios no comportamento, hiper-agitação, dificuldades de concentração e de aprendizagem) , é significativamente maior do que o de meninas (70\% de crianças do sexo masculino e 30\% do sexo feminino) . A grande maioria dessas crianças é encaminhada pelas próprias escolas; os demais vêm encaminhados pelo Posto de Saúde, mas geralmente a pedido da escola. Se considerarmos que não há praticamente diferença na proporção de meninas e meninos matriculados na rede municipal de ensino da cidade de Novo Hamburgo (52\% são meninos e 48\%, meninas), esse dado chama a atenção. Constatamos, por um lado, o sofrimento psíquico desses meninos para se ambientar e interagir num espaço que parece fechado para eles e, por outro, o desespero de professoras, que se sentem acuadas, agredidas, desrespeitadas e impotentes para lidarem com essas situações.

De que forma, ou de que posição, a escola pode operar efeitos que não sejam sintomáticos, mas geradores de aprendizagem e crescimento? E que resposta a clínica psicanalítica pode dar aí, que não seja simplesmente atender essa demanda cada vez maior de tratar "estes guris medonhos".

Focarei mais especificamente as sintomas da agressividade e da agitação, pois, além de serem as queixas mais freqüentes, são os que provocam reaçães mais graves e descontroladas por parte da família e da escola. São meninos que, geralmente, lotam os serviças de neurologia antes de chegarem para tratamento psicoterapêtico.

As professoras geralmente se identificam com a criança agredida, principalmente se for uma menina. A leitura que fazem das reações e atos desses meninos com comportamento agressivo, é sempre a mesma e carregada de indignação, de raiva e de uma visão moral, que mal encobre um discurso de vitimização da mulher submetida à força física do homem. Afirmo isso porque é freqüente, nos relatos de algumas professoras ou diretoras de escolas, que a descrição desses meninos e de seu comportamento os situa numa posição de homens, de adultos, que colocariam em risco as outras crianças e até mesmo as professoras, justificando atos descontrolados ou repressão severa por parte destas, quando não, acionando instâncias da lei, como o conseIho Tutelar ou a Guarda Municipal para coibir atos agressivos que thes parecem impossíveis de serem contidos, mesmo que se trate de uma criança pequena, de 7, 8 ou 9 anos, por exemplo. Quero deixar claro que não se trata de uma posição acusatória em relação às professoras. Antes, parece-me haver aí um reflexo do discurso familiar e social que localiza o mascul ino do lado da violência, da força bnuta, do desadaptado... As professoras, que têm uma turma com cerca de trinta crianças para educarem, 
vêem-se pressionadas e despreparadas para intermediarem conflitos e situações que, na maioria das vezes, são plenamente suscetíveis à interferência da palavra - uma palavra sustentada em transferência - e poderiam se resolver no âmbito escolar, geralmente dentro da própria sala de aula.

\section{MAS, ENTÃO, O QUE FRACASSA AÍ?}

Esses meninos com problemas de agressividade, agitação motora, dificuldade de concentração e de aprendizagem, na grande maioria são diagnosticados apressadamente com uma sigla: TDAH (Transtorno de Déficit de Atenção e Hiper-atividade) . Hoje o alastramento desse diagnóstico vem sendo discutido, inclusive em alguns meios médicos (conforme reportagem da Revista Cartacapital, de 11/08/04), nos quais se questiona a rapidez do diagnóstico e a general ização da medicação das crianças. A revista aponta o óbvio, mas facilmente esquecido: o mundo "hiper-ativo" em que vivemos, dotado de excessos, velocidade, superficialidade, agitação, altura do descartável, fragmentação, ausência de sentido etc. A reportagem chega a declarar que "... a hiper-atividade revela-se mais do que uma novidade: ela é, talvez, a mais contemporânea das doenças" (p. 11). Nessa mesma matéria, o médico Carlos Alberto da Costa e Silva, especialista em saúde mental e ex-diretor da Organização Mundial de Saúde (OMS) , alerta para a superficialidade e rapidez com que se diagnostica atualmente essa "doença", afirmando que aproximadamente 65\% dos diagnósticos de TDAH são incorretos. Surpreende-nos, por se tratar de uma autoridade do próprio meio médico a dizer tal coisa. Ele elenca uma série de at tras hipóteses e situações para explicar tais sintomas apresentados pelas crianças - em grande parte meninos - de ordem fisiológica, familiar, social au altural, sem no entanto considerar as causas psíquicas. Porém, com bomsenso, recomenda tempo e prudência na elaboração do diagnóstico e na intervenção medicamentosa, aconsel hando: "O mais importante é a análise minuciosa da história clínica do paciente, um exame clínico cuidadoso, a interação com a família e paciência para avir." (Revista Cartacapital, 11/08/04, p.14-grifomeu)

A disseminação dos manuais para identificação dos passíveis casos de TDAH criou o estereótipo do hiper-ativo, carapaça que serve em qualquer menino mais agitado, ou que não corresponda ao padrão de comportamento esperado pela escola. A criança é encaminhada para o médico já portando esse estigma e, chegando lá, quase sempre ouve a confi imação desse diagnóstico e ga- 
nha um remedinho ("remendinho") para tomar. Nos casos em que a criança não é medicada, há reclamação das mães e das professoras, geralmente, que depositam no medicamento a esperança de que o filho ou o aluno "defeituaso" seja consertado. O que se espera é uma mudança radical e imediata no comportamento, sem que nada em tomo da criança mude au precise ser interrogada.

A escola, nos dias de hoje, representa um universo maciçamente feminino, formado por professoras, diretoras, supervisoras e merendeiras. É um lugar onde as mulheres predominam, decidem, comandam. Como será para esse universo eminentemente feminino lidar com o masculino? Por que os meninos, muito mais do que as meninas, respondem com tais sintomas?

É preciso lembrar que a agressividadeé constitutiva do stjeito. Ela surge fundamentalmente na experiência fratema na tenra infância, emque um igual é tomado como inimigo, na lógica do en au ele. Esse outro, visto como rival frente à mãe, é sempre ameaçador, ao mesmo tempo em que funciona como duplo. Isso se vê claramente, por exemplo, na experiência do transitivismo, na qual a criança é a que bate e, ao mesmo tempo, a que foi agredida. Lacan (1938) já apontava isso a que ele designou inicialmente de "Complexo de Intrusão", num de seus primeiros textos, A Família. Num artigo posterior, Agressividade em Psicanálise (Lacan, 1948), segue trabaIhando esse tema do complexo de intrusão ou complexo fratemo. Retoma a questão do ciúme - referindo o relato de Santo Agostinho da observação de uma cena de amamentação - não apenas como rivalidade vital, mas como expressão de uma identificação. "Aqui realiza-se este paradoxo: que cada parceiro confunde a parte do outro com a sua própria e identifica-se com ele. ... O mesmo é dizer que a identificação, específica das condutas sociais, neste estádio, se funda sobre um sentimento do outro, que não se pode senão desconhecer sem uma concepção corrente do seu valor completamente imaginário (Lacan, 1938 , p. 39). Enfatiza também a questão da necessidade de uma semelhança entre os sujeitos: "Parece que a imago do outro é ligada à estrutura do corpo próprio e mais especialmente das suas funções de relação, por uma certa semelhança objetiva" (1938, p. 40). Ou seja, há uma ambigüidade originária na relação com o outro, o semelhante, em que há uma operação de identificação por trás da rivalidade, mas também um processo de diferenciação em relação ao autro. Essa agressividade especular é fundante do eu. É correlativa da tensão narcísica no advento do sujeito e não pode, nas palavras de Lacan, "... ser concebida, se não tiver sido preparada por uma identificação primária que estnuture o sujeito como rival izante consigo mesmo" (Lacan, 1948, p. 33). Eéo que Freud (1919) já havia postulado no texto $O$ estranho, quando fala do duplo como constituinte da identidade do eu.

É no atravessamento do Édipo, pela qperação de identi ficação seaundária a partir da introjeção da imago parental, que se abrem as portas para a sublimação, a qual libera o 
sujeito das amarras da rivalidade acentuada em direção ao interesse pelo que está a sua volta. "Assim, a identificação edipiana é aquela pela qual o sujeito transcende a agressividade constitutiva da primeira individuação subjetiva" (Lacan, 1948, p. 34). As teorias sexuais infantis têm aí o seu ápice e, a partir de então, o semelhante pode ser tomado numa relação fraterna que não seja dominada pela agressividade, mas intermediada pelo prazer lúdico e da convivência, pela arriosidade, pela fantasia, pelo interesse nos dbjetos e instrumentos da realidade.

Se a agressividade é constitutiva da subjetividade, por outro lado ela pode ser produzida ou exacerbada a partir do meio e da rede disarsiva que sustenta a criança.

Vivemos numa cultura que tenta banir a agressividade, o conflito, num ideal de harmonia fadado ao fracasso. Vemos isso freqüentemente na relação de pais e fi lhos, em que aqueles tentam economizar o conflito, a tensão inevitável na relação intergeracional, cedendo incondicionalmente ao apelo das crianças (ainda que seja da criança introjetada neles próprios) . É uma cultura que faz a apologia da igualdade, na qual a diferença sexual, a dessimetria entre adultos e crianças, a diferenciação nas funçães do pai e da mãe tendem a ser apagadas em formações imaginárias que obliteram a dimensão da falta.

Vou me deter um pouco a examinar essas funções do pai e da mãe. Leclaire (2001) nos ajuda a pensar, a partir de suas colocaçães sobre o lugar que no imaginário social é con- ferido à mulher, numa superposição do significante mulher-mãe, no qual o mito da mãe fálica nos seduz e horroriza ao mesmo tempo. Podemos ficar tentados a contrapor que na atualidade, na cultura ocidental, a mulher não está mais identificada nesse único lugar: o de mãe. As mulheres contemporâneas teriam se libertado desse modelo - liberdade resultante do movimento feminista, dos métodos contraceptivos e da entrada ofensiva no mercado de trabalho. No entanto, parece que o sentimento de culpa que manifestam em relação a um ideal feminino que daria conta de tudo irrepreensivelmente (casa, fi thos, mariob, carreira, ideais estéticos e intelectuais) denuncia uma dívida ao mito da super-mulher-mãe.

Maria Rita Kehl (2001) corrobora essa visão, ao trazer-nos um questionamento sobre a definição de família desestruturada, quando se fala nas mudanças e novas configuraçães pelas quais o modelo tradicional de família conjugal vem passando ultimamente. coloca que a idéia de família desestruturada - e nas instituiçõ̃es sociais, de saúde ou de educação se ouve isto a toda a hora - é tributária da culpa neurótica em relação ao ideal de família nuclear tradicional: pai, mãe e fil hos biológicos convivendo juntos, em que a figura da mãe ocupava o lugar cental.

"Enfim: a família estruturada produziu a histeria e a neurose dosessiva como sintomas emergentes do mal-estar no final do século XIX. A histeria como sintoma do desajuste das mulheres em relação ao lugar que lhes era destinado e também em 
relação a um ideal de feminilidade impossível de se habitar. A neurose obsessiva como sintoma da impossibilidade de um homem afirmar sua virilidade e ao mesmo tempo submeter-se à autoridade do chefe da famúlia patriarcal, tal como ela estava constituída. Além disso, a família estnuturada produziu a fixação edipiana dos fillhos à mãe, que não é a mesma coisa que o atravessamento do Complexo de Édipo. Não é obrigatório que a passagem pelo Édipo produza fixação dos fil hos à mãe. Mas para sustentar o lugar da mãe de família burguesa como rainha do lar, que era uma necessidade da sociedade capital ista emergente, produziu-se uma enorme quantidade de saberes - filosóficos, médicos, literários, desde Rousseau, no século XVIII - que insistiam sobre a 'natureza' feminina como estreitamente definida pelas funções reprodutivas das mulheres"' (Kehl, 2001, p. 32) .

Se esse ideal de famúlia permanece no imaginário social, inevitavelmente as novas configurações familiares, a saída da mulher de casa para o campo profissicnal, intelectual ou político, serão sentidas como deficitárias ou falhas em relação ao modelo anterior.

Aqui retomamos uma contribuição de Leclaire, para quem "... nossa grande preocupação é fazer o mesmo, e que esse mesmo é sempre feito a partir de um único modelo, que é aquele imaginário, da mãe. Inconscientemente, fantasisticamente, o outro é sempre reduzido ao mesmo, ou pelo menos é o que predomina. Vivemos num mundo homo" (2001, p. 32) . E, logo a seguir, complementa, explicando que "o que ela [uma mulher] teria a produzir realmente é diferença, é sexo, e não apenas filhos; algo de diferente daquilo ao qual ela é culturalmente submetida" (p. 33) .

Com a instigante pergunta "Como pensar o sexo sem a alteridade?" , esse autor questiona em nossa cultura a diferença entre a função da mãe e a função do pai, em que há uma imaginarização e generalização do espaço matemo. "A mãe é uma boa imagem de um paraíso ou de um inferno. Para manter esse sonho, tudo, o mundo inteiro se toma então representação desse pedacinho do céu, desse outro mundo que é o corpo materno. A representação da mãe se toma o grande ídolo, e a atividade do homem consiste em fabricar ídolos, seja um metrô ou um arranha-céu, um sistema filosófico bem fechado ou uma teoria pessoal. Sua grande atividade é construir espaços fechados" (p. 36) . E acrescenta não ser fácil para a mulher escapar da universalidade da fantasia masculina, representada na polaridade entre a mãe e a puta.

Essa fantasia prende homens e mulheres, acentuando uma rivalidade sexual, ao mesmo tempo em que propõe o apagamen- 
to das diferenças. "Somos todos iguais: somos todos mães disfarçadas de homens-mulheres" , provoca Leclaire (2001, p. 39) . No extremo, a disputa seria para ver quem é melhor mãe!

Nesse quadro, o pai encontra muita dificuldade para se posicionar num discurso outro que não o matemo, seja pela idealização da mãe, seja pela não autorização a romper com esse discurso. São homens que, nas entrevistas clínicas, vencida uma certa inibição inicial para contestar a figura da "VĔe", têmum posicionamento diferente em relação aos filhos, a sua educação ou a situações de conflito familiar. Mas sua palavra sempre thes parece fraca ou inoperante ante o saber materno, que se coloca com maior valor de legitimidade frente ao fi tho, pelo fato de que foi ela quem o gerou, deu à luz, amamentou. A facilidade com que as mulheres dispensam o homem do exercício da paternidade, de seus direitos, dbrigações e cuidados com a prole - sem falar nas novas formas de fert ilização que prescindem completamente da figura do pai -, reiterama prevalência da função da mãe, alicerçada na proximidade comporal. É como se a patemidade, que se afima por autros princípios que não o biológico, estivesse à deriva, sem o garante simbólico que atorgasse ao pai um lugar diferente na criação do filho, mas de igual importância que o lugar materno este sempre incontestável.

Geneviève de Parseval (1986), no seu livro A parte db pai, considera que há uma negação da patemidade na cultura ocidental contemporânea. Trabalha os rituais de res- 
guardo paterno após o parto, presente em algumas culturas, como reconhecimento social da participação do pai na concepção e no nascimento. E sustenta que na nossa cultura os sintomas psicosscmáticos do futuro pai durante a gravidez e/ou nascimento do filho, substituem o ritual simbólico inexistente. Faz um estudo pormenorizado das diferentes teorias sobre o parto que ditam a conduta parental frente ao nascimento do filho, disparando: "É essencial ver que o conhecimento - aqui conhecimento biológico e médico - é sempre 'utilizado' por uma cultura em função dos seus objetivos ideológicos (a um só tempo inconscientes e conscientes). Assim é que nossa sociedade se serviu de seus conhecimentos científicos em matéria de fisiologia para fazer da 'fabricação' de uma criança um assunto exclusivamente materno e feminino, excluindo o pai de uma ponta à outra do processo" (p. 32) .

Do ponto de vista da psicanálise, a função do pai se desobbra emmúltiplas representações: falamos de pai real, pai simbólico, pai imaginário; metáfora patema, significante nome-do-pai, pai encamado etc. É como se precisássemos de muitas palavras para tentar definir o pai e ele sempre nos escapasse. Enquanto que da mãe, uma palavra universal basta ("Nãe só tem uma!" - expressão popular que atesta a garantia da matemidade) . É como se a mãe estivesse do lado do real e o pai do lado da representação.

Mas o que sustenta esse lugar de representação do pai junto ao filho? Lacan vai dizer que seu lugar está sustentado na medida em que ele, o pai, é o alvo do desejo da mãe de seu fil lho e, mais precisamente, que é no valor que a sua palavra ocupa para ela que se sustenta a função do pai. De novo, todo o poder às mães! E toda a responsabilicade!

Para Lacan (1956-57), não se trata do pai na família, mas do pai no Édipo, ou seja, na estrutura. Ele não fala da presença ou da ausência do pai, mas da operacionalidade ou não de sua função. Frik Porge, em Os nomes do pai em Jacques Lacan, afirma textualmente: "O pai é uma metáfora" (1998, p. 40). E define logo a seguir: "O Nome-do-pai é a capacidade normativizante do pai, enquanto ele não se conforma a uma média, mas 'faz rachar' as normas matemas para instituir novas. Sua perversão é a versão da mudança de norma que ele institui por relação ao desejo da mãe" (p. 41) . É no Édipo que essa função normativizante do Nome-do-pai opera como metáfora patema e alarga as possibili idades simbólicas para a criança. 0 problema é que às vezes falamos como se essa função pudesse ser exercida sem sujeito; metaforizamos o pai a tal ponto que não sabemos mais a que, ou a quem estamos nos referindo. certo uso que fazemos da teoria lacaniana pode reforçar o mito 
contemporâneo da descartabilidade do pai. O que fica aí de fora, mais do que a figura do pai, é a sua eficácia como portador da diferença (e se trata sempre da diferença sexual). Pois é justamente o registro da diferença que pode fazer frente ao incesto.

Leclaire (2001) é categórico ao afirmar: "O que é proibido na nossa sociedade não é o incesto. Na verdade, o que é proibido é sair do incesto. Fntão, só resta a violência" (p. 57) . Afirmação muito forte, que poderá soar descabida. Mas se nos reportarmas à experiência clínica, no consultório ou nas instituiçães, é cada vez maior o número de casos de crianças, que chegam para tratamento, submetidas as suas mães, presas ao discurso matemo. O pai, quando não totalmente inexistente, vê-se impedido em sua função de corte desse gozo, como se o enodamento das três registros de sua função se desamarrasse e ele não encontrasse um lugar de onde operar. No lugar da diferença, se erige a passividade, a desautorização, a onissão ou a ausência. Como reação a esse lugar de dejeto, em que sua virilidade se vê atacada, commente surge a violência como resposta imediata ou tardia: a força física, último reduto do macho viril!

Parece-me que a violência não surge como resposta apenas do lado do pai, mas do lado do filho. Não só por um recurso de identificação masculina. O menino que se vê engolfado num mundo feminino, dominado pela mãe, sem um mínimo de garantias de interdição ao conpo materno, ao mesmo tempo em que ele goza nessa proximidade incestuo- 
sa com a mãe, se asfixia nesse gozo mortífero, e as reaçães corporais exacerbadas de agitação e agressividade são expressões de um eu corporal tentando rebelar-se a esse domínio não interditado pela palavra. Marco eu-corporal, não só no sentido de lembrar que o Eu é antes de tudo corpo (imagem) na sua representação psíquica, mas de enfatizar que na fragilidade simbólica em que essas crianças se encontram, o conpo é tudo que Ihes resta de uma afirmação de identidade ameaçada frente à angústia de castração. Porém não se trata, neste caso, da castração simbólica, e sim da forma mais bnuta e mortífera da castração: o temor de ser engolido pela mãe.

Aqui abro para um fragmento da clínica: um menino a quem chamarei de Márcio, 10 anos, chega para tratamento com queixas por parte da escola e da mãe: é desatento, com dificuldades de aprendizagem, hiper-ativo. Duplamente reprovado na escola: não passou de ano e não consegue se relacionar com as colegas. Desafia as professoras o tempo todo, não brinca no recreio nem participa das aulas de educação física. Fpisódios de agressividade são recorrentes. A mãe (pois o pai não comparece num primeiro momento) tem um discurso melancólico, que beira ao delírio, emque não reconhece neste filho uma continuidade em relação àquele que carregava em seu ventre. Narra o período de gravidez como sendo muito feliz, no qual imaginava um bebê lindo, sorridente e que não lhe desse trabalho. Os problemas começaram no final da gestação, quando Márcio começou a movimentar-se mais 
ativamente no útero. Ela diz: "Ele me chutava, como um monstro." Esse filho - que por sinal nasceu loirinho, com cara de anjo - (ela trouxe algumas fotos dele quando nenê), não se coaduna com a imagem congelada de um bebê que a mãe carrega. Toda a atividade e vitalidade dessa criança foi tomada como agressiva pela mãe, sendo fortemente repreendida. Ela conseguiu ocupar-se dos cuidadas corporais do filho, mas deixou claro o quanto lhe foi penoso; "foi tudb diferente do que eu imaginava", nos diz. O diferente, nestecaso, éterrorífico.

O pai mostra-se mais amoroso e tolerante em relação ao fi tho, acha que as maiores dificuldades de Márcio estão na relação com a mãe, sempre a exigir dele autra coisa, mas se sente completamente impotente para interferir nesse laço. Queixa-se de que a mulher está sempre doente e nervosa e que não dá espaço para que o filho possa ser criança. Mas não consegue intervir efetivamente, ficando num papel de espectador.

Márcio aceita participar de um grupo terapêutico de meninos e meninas mais ou menos da sua idade, na condição de que possa escoIher: "Vou experimentar vir uma vez para ver como é." Fica no grupo durante um ano, com dificuldade de inserir-se nas atividades, brincadeiras ou conversa grupal, mas muito atento e ligado, principalmente nas gurias, com quem rivalizava e implicava o tempo todo. Ao longo desse ano de tratamento, sua conduta na escola mudou e ele começou a se integrar e a aprendizagem a deslanchar. Agora a queixa da mãe é que ele está se tomando rebelde, queren- 
do sair para a rua com os amigos, andar de skate, enfim, aproximando-se de uma posição adolescente. Ao final do atendimento em grupo, ele foi encaminhado para um tratamento individual, com um analista homem. Novamente reluta, diz que não quer, mas acaba vindo. Depois de alguns meses continua em tratamento e estabelece com o terapeuta uma relação de parceria e competitividade através dos jogos, o que lhe permite transitar pelo universo mascul ino sem o peso que esses traços carregam para a mãe. Observo, na sala de espera, nas sessões ao ar livre, que ele vem assumindo uma nova postura corporal : mais apropriado de seu conpo, movendo-se com mais destreza e coordenação; deixou crescer os cabelos, apesar dos protestos matemos.

Mas, e a escola? Qual a sua posição frente a essa problemática? O que temos visto, na maioria das vezes, é a escola identificada na posição da mãe, queixosa e exasperada com esses meninos agressivos e "hiper-ativos" . A escola, ao colar-se ao discurso matemo de domesticação da criança, toma como sintomático e intolerável qualquer produção conporal fora do esperado, não conseguindo atribuir-Ihe nenhum outro sentido que o da violência. 0 discurso da agressividade por parte dos meninos, justifica toda uma série de atos violentos, repressores au desrespeitosos em relação ao aluno. Em alguns casos, acontece de a professora, na tentativa de incutir-lhe um modelo de bom comportamento, comparar um desses meninos com a aluna mais bem comportada, inteligente, dócil e querida, enfatizando a distância entre eles dois como um déficit por parte do aluno em questão. Ou seja, o modelo que ele deveria seguir é o modelo feminino. Feminino também é o universo escolar, em que a presença de professores do sexo masculino é incipiente.

Então, onde encontrarão referências mascul inas, os nossos guris? A escola, muitas vezes, reproduz um modelo de educação cerceadora, dirigida a determinados padrões em moda, como o modelo do homem sensível, bem arrumado, enfeitado, gentil, enfim, "uma moça".

Comeau (1997), num livro que traz idéias interessantes, apesar do título um tanto apelativo, Pai ausente, fi lho carente: 0 que aconteceu com os homens?, também enfatiza a importância do pai como interditor do poder matemo em relação ao filho, função que lhe parece estar extremamente difícil para os homens exercerem.

"Na verdade o pai, ao provocar o fim da união total entre a mãe e seu filho, rompe a identificação entre o desejo e o dbjeto do desejo. Isso significa que a criança poderá tomar consciência do desejo como sendo um fato psíquico que possui uma experiência em si, uma existência independente do fato de esse 
desejo encontrar ou não satisfação na realidade exterior. (...) Esta frustração do incesto permite também a separação entre natureza e cultura. Um homem que vive fundido ao seu interior, vive também fundido ao mundo exterior. Ele toma-se a cultura e fica identificado com os estereótipos em voga. Se, para ser um homem, é preciso ter ar de macho, ele terá ar de macho. Se é preciso ser meigo, ele será meigo. Ou seja, um homem que permanece principalmente identificado à mãe não tem acesso a sua própria individualidade; ele permanece o joguete de seu inconsciente e das modas sociais" (p. 41) .

Se a escola estiver, ela também, escrava das "modas sociais" reproduzirá esses modelos, e tudo o que se afastar das normas de comportamento esperado será considerado psicopatológico ou desajustado. Agora, se a escola tiver frestas de arejamento, instâncias de furo no discurso dominante - e no caso das instituições escolares o discurso dominante é o feminino -, pode vir a se configurar como um oásis neste mundo tão sem referências para nossas crianças, principalmente para os guris. Aliás, guri é um significante quase em extinção, não se usa mais!

Penso que a escola, na medida em que pode ser representativa das leis simbólicas, do fomento à singularidade na coletividade, da solidariedade entre semelhantes, da intermediação da palavra em situações de atrito, dos espaços altemativos de circulação e convivência, dos contínuos desafios intelectuais e experiências comparti lhadas, re- 
presenta um caldo cultural e afetivo decisivo para a estruturação de muitas crianças, se estiver regida pela ética da diferença.

REFERÊNCIAS BIBLIOGRÁFICAS
NOTAS

1 Trabalho apresentado no Congresso da APPOA "A Masculinidade", realizado em Porto Alegre, de 22 a 24 de autubro de 2004.

2 Refiro-me à psicóloga Cláudia Muller.

Athayde, P. e Lobo, F. Este mundo é hiperativo. Reportagem da Revista Cartacapital, de 11 de agosto de 2004 .

Comeau, G. (1997) . Pai ausente, filho carente: o que aconteceu com os homens? (L. Jahn, trad.) Săo Paulo: Brasiliense.

Freud, S. (1919) . Lo Siniestro. In Cbras Completas de Sigmud Fread (L.I-Ballesteros y de Torres, trad.) (Tomo III, p. 2483-2505), $3^{\text {a } e d . ~ M a d r i d: ~ B i b l i o t e c a ~ N u e v a, ~ s / d . ~}$

Kehl, M. R. (2001) . Lugares do feminino e do masculino na família. In: Comparato, M.C.M. e Monteiro, D. S. F. (Org.) . A criança na contemporaneidade e a psicanálise-Família e Sociedade: Diálogos Interdisciplinares. Vol. I. São Paulo: Casa do Psicólogo.

Lacan, J. (1938) . A Famí7ia. Lisboa: Assírioe Alvim, 1981.

(1948) . A Agressividade em Psicanálise. In: Cademas Lacan - $1^{2}$ Parte. Publicação intema da Associação Psicanalítica de Porto Alegre. (M.R Pereira e F. Roche, trad.) . Porto Alegre: APPOA, s/d.

(1956-57) . O Seminário, Iivro 4: A relação de objeto. (D. D. Estrada, trad.) Rio de Janeiro: Jorge Zahar, 1995.

Leclaire, S. (2001) . Escritos Clínicos. (L. Nagalhães, trad.) Rio de Janeiro: Jorge Zahar. Parseval, G. D. (1986) . A parte ob pai. (L. A. Watanabe e T. C. Stumer, trad.) Porto Alegre: L\&PM.

Porge, E. (1998) Os nomes do pai em Jacques Lacan: pantuaçães eproblenáticas. (C. P. de Almeida, trad.) Rio de Janeiro: Companhia de Freud.

Recebido em autubro/2004. Aceito em novembro/2004. 